Purdue University

Purdue e-Pubs

CTRC Research Publications

Cooling Technologies Research Center

2014

\title{
Confined Jet Impingement with Boiling on a Variety of Enhanced Surfaces
}

M. Rau

Purdue University

S V. Garimella

Purdue University, sureshg@purdue.edu

Follow this and additional works at: http://docs.lib.purdue.edu/coolingpubs

Rau, M. and Garimella, S V., "Confined Jet Impingement with Boiling on a Variety of Enhanced Surfaces" (2014). CTRC Research Publications. Paper 242.

http://dx.doi.org/DOI: 10.1115/1.4027942

This document has been made available through Purdue e-Pubs, a service of the Purdue University Libraries. Please contact epubs@purdue.edu for additional information. 


\section{Confined Jet Impingement With Boiling on a Variety of Enhanced Surfaces}

\author{
Matthew J. Rau \\ School of Mechanical Engineering, \\ Purdue University, \\ 585 Purdue Mall, \\ West Lafayette, IN 47907
}

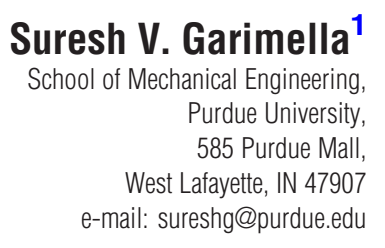

Confined jet impingement with boiling offers unique and attractive performance characteristics for thermal management of high heat flux components. Two-phase operation of jet impingement has been shown to provide high heat transfer coefficients while maintaining a uniform temperature over a target surface. This can be achieved with minimal increases in pumping power compared to single-phase operation. To investigate further enhancements in heat transfer coefficients and increases in the maximum heat flux supported by two-phase jet impingement, an experimental study of surface enhancements is performed using the dielectric working fluid HFE-7100. The performance of a single, $3.75 \mathrm{~mm}$-diameter jet orifice is compared across four distinct copper target surfaces of varying enhancement scales: a baseline smooth flat surface, a flat surface coated with a microporous layer, a surface with macroscale area enhancement (extended square pin fins), and a hybrid surface on which the pin fins are coated with the microporous layer. The heat transfer performance of each surface is compared in single-and two-phase operation at three volumetric flow rates $(450 \mathrm{ml} / \mathrm{min}, 900 \mathrm{ml} / \mathrm{min}$, and $1800 \mathrm{ml} / \mathrm{min})$; area-averaged heat transfer parameters and pressure drop are reported. The mechanisms resulting in enhanced performance for the different surfaces are identified, with a special focus on the coated pin fins. This hybrid surface showed the best enhancement of all those tested, and resulted in an extension of critical heat flux (CHF) by a maximum of 2.42 times compared to the smooth flat surface at the lowest flow rate investigated; no increase in the overall pressure drop was measured. [DOI: 10.1115/1.4027942]

Keywords: jet impingement, two-phase cooling, boiling, surface enhancement, HFE7100 , microporous coating

\section{Introduction}

The combination of two highly effective heat removal mechanisms-boiling and jet impingement—can lead to the design of efficient and compact technologies that can handle the high heat fluxes dissipated in a variety of applications such as high-performance computing, power electronics, and gas turbines. Much is known about the influence of geometric and operational parameters on single-phase jet impingement, which allows optimization of the pressure drop, flow rate, temperature uniformity, and heat removal capacity to meet specific constraints. While singlephase jet impingement has been thoroughly investigated [1,2], two-phase operation, where the coolant is allowed to boil on the heated surface, is less well-understood. Superposition of phasechange heat transfer on the high convective heat transfer coefficients achieved with single-phase jet impingement can enhance heat removal capability while also improving temperature uniformity [3-7]. Sweeping of vapor from the heated surface by the impinging liquid jet also greatly extends $\mathrm{CHF}$ as compared to pool boiling [8-10].

Phase change with dielectric fluids has recently received much attention because of the capacity for direct contact with electronic devices. The engineered hydrofluoroether (HFE) fluids produced by $3 \mathrm{M}$ are available with a wide range of boiling temperatures (from $34^{\circ} \mathrm{C}$ to $131^{\circ} \mathrm{C}[11]$ ), allowing their use at a variety of desired operating temperatures. HFE fluids have no ozone

\footnotetext{
${ }^{1}$ Corresponding author.

Contributed by the Heat Transfer Division of ASME for publication in the Journal of Heat Transfer. Manuscript received January 24, 2014; final manuscript received June 24, 2014; published online July 29, 2014. Assoc. Editor: Jim A. Liburdy.
}

depletion potential and a low global warming potential. Many recent heat transfer enhancement strategies have been explored with these coolants.

It has long been known that the addition of surface enhancements can greatly improve phase-change heat transfer performance. Webb [12-14] reviewed the chronological progression of boiling enhancement geometries; a review focused on boiling enhancements in dielectric fluids was conducted by Honda and Wei [15]. Nucleation sites can be enhanced by creating cavity geometries that trap vapor on the surface to promote bubble nucleation, and include attached promoters (such as meshes and screens), coatings, and increased surface roughness [12].

Porous coatings offer a relatively easy means of fabricating interconnected reentrant-type cavities that form stable nucleation sites and create very effective boiling surface enhancements. Porous coatings produced with different morphologies and fabrication techniques have been investigated; experimental parameters explored in the literature are summarized in Table 1. Metallic porous coatings in particular have received much attention. Bergles and Chyu [16] investigated commercial boiling enhancements and found that a brazed porous metallic coating (Union Carbide High Flux) increased boiling heat transfer coefficients drastically compared to a smooth surface; however, the surface temperature excursion at the onset of nucleate boiling (ONB) was exacerbated with the highly wetting fluid, R-113. In a similar study, Marto and Lepere [17] also investigated the High Flux porous metallic coating, and demonstrated improvement in nucleate boiling heat transfer coefficients of 4-5 times. In a study of another commercially available metallic coating, Thiagarajan et al. [18] compared the performance of pool boiling and spray impingement boiling of the coolant HFE-7100 on surfaces coated 
Table 1 Summary of experimental parameters used for porous coating boiling enhancement in the literature

\begin{tabular}{|c|c|c|c|c|c|c|c|}
\hline References & Fluid & $\begin{array}{l}\text { Heater } \\
\text { configuration }\end{array}$ & $\begin{array}{c}\text { Test } \\
\text { conditions }\end{array}$ & $\begin{array}{l}\text { Enhanced } \\
\text { surfaces }\end{array}$ & Thickness & $\begin{array}{l}\text { Particle } \\
\text { diameter }\end{array}$ & $\begin{array}{l}\text { Porosity } \\
(\%)\end{array}$ \\
\hline Bergles and Chyu [16] & Water, R-113 & $\begin{array}{l}25 \text { mm o.d. cylindrical surface oriented } \\
\text { horizontally }\end{array}$ & Saturated pool boiling & Union Carbide High Flux & $0.38 \mathrm{~mm}$ & $<74 \mu \mathrm{m}$ & $50-65$ \\
\hline Marto and Lepere [17] & R-113, FC-72 & $\begin{array}{l}15.8 \mathrm{~mm} \text { o.d. cylindrical surface oriented } \\
\text { horizontally }\end{array}$ & Saturated pool boiling & $\begin{array}{l}\text { Union Carbide High Flux } \\
\text { Wieland Gewa-T } \\
\text { Hitachi Thermoexcel-E }\end{array}$ & $\begin{array}{l}0.08 \mathrm{~mm} \\
0.19 \mathrm{~mm} \\
1.02 \mathrm{~mm}\end{array}$ & $<74 \mu \mathrm{m}$ & - \\
\hline You et al. [21] & FC-72 & $\begin{array}{l}10 \mathrm{~mm} \times 10 \mathrm{~mm} \text { flat, horizontally oriented } \\
\text { film heater }\end{array}$ & Saturated pool boiling & $\begin{array}{l}\text { Alumina particles held in contact with } \\
\text { van der Waals forces or thin glue layer }\end{array}$ & - & $<3 \mu \mathrm{m}$ & - \\
\hline El-Genk and Ali [20] & PF-5060 & $\begin{array}{l}10 \mathrm{~mm} \times 10 \mathrm{~mm} \text { flat, horizontally oriented } \\
\text { copper substrate }\end{array}$ & Saturated pool boiling & $\begin{array}{l}\text { Dendritic copper surfaces created with } \\
\text { electrochemical deposition }\end{array}$ & $33-146 \mu \mathrm{m}$ & - & $7-74$ \\
\hline O'Connor and You [22] & FC-72 & $\begin{array}{l}5.1 \mathrm{~mm} \times 16.5 \mathrm{~mm} \text { flat, horizontally } \\
\text { oriented film heater }\end{array}$ & Saturated pool boiling & Paintable porous coating (silver flakes) & $25 \mu \mathrm{m}$ & $3-10 \mu \mathrm{m}$ & - \\
\hline Chang and You [23] & FC-72 & $\begin{array}{l}10 \mathrm{~mm} \times 10 \mathrm{~mm} \text { flat, horizontally oriented } \\
\text { copper substrate }\end{array}$ & Saturated pool boiling & $\begin{array}{l}\text { Paintable porous coating (diamond } \\
\text { particles) }\end{array}$ & $30-250 \mu \mathrm{m}$ & $2-70 \mu \mathrm{m}$ & $40-48$ \\
\hline Chang and You [24] & FC-72 & $\begin{array}{l}10 \mathrm{~mm} \times 10 \mathrm{~mm} \text { flat, horizontally oriented } \\
\text { copper substrate }\end{array}$ & Saturated pool boiling & $\begin{array}{l}\text { Paintable porous coatings (aluminum, } \\
\text { copper, diamond, silver particles) }\end{array}$ & $30-100 \mu \mathrm{m}$ & $<50 \mu \mathrm{m}$ & - \\
\hline Chang and You [25] & FC-87, R-123 & $\begin{array}{l}12.7 \mathrm{~mm}-17.2 \mathrm{~mm} \text { o.d. cylindrical surface } \\
\text { oriented horizontally }\end{array}$ & Saturated pool boiling & $\begin{array}{l}\text { Paintable porous coating (aluminum particles) } \\
\text { Low fins } \\
\text { Low fins coated with paintable coating } \\
\text { Union Carbide High Flux } \\
\text { Woverine Turbo-B }\end{array}$ & $\begin{array}{l}50 \mu \mathrm{m} \\
880 \mu \mathrm{m} \\
930 \mu \mathrm{m} \\
400 \mu \mathrm{m} \\
600 \mu \mathrm{m}\end{array}$ & $<20 \mu \mathrm{m}$ & - \\
\hline Rainey et al. [26] & FC-72 & $\begin{array}{l}10 \mathrm{~mm} \times 10 \mathrm{~mm} \text { flat, horizontally oriented } \\
\text { copper substrate }\end{array}$ & $\begin{array}{l}\text { Subcooled and gas-dissolved } \\
\text { pool boiling }\end{array}$ & $\begin{array}{l}\text { Paintable porous coating } \\
\text { (aluminum particles) }\end{array}$ & $50 \mu \mathrm{m}$ & $<20 \mu \mathrm{m}$ & - \\
\hline Arik et al. [27] & FC-72 & $\begin{array}{l}6.5 \mathrm{~mm} \times 6.5 \mathrm{~mm} \text { silicon chip, horizontally } \\
\text { oriented }\end{array}$ & $\begin{array}{l}\text { Subcooled and gas-dissolved } \\
\text { pool boiling }\end{array}$ & $\begin{array}{l}\text { Paintable porous coating } \\
\text { (diamond particles) }\end{array}$ & $50-75 \mu \mathrm{m}$ & $8-12 \mu \mathrm{m}$ & - \\
\hline Thiagarajan et al. [18] & HFE-7100 & $\begin{array}{l}10 \mathrm{~mm} \times 10 \mathrm{~mm} \text { flat, vertically oriented } \\
\text { copper substrate }\end{array}$ & $\begin{array}{l}\text { Pool and spray impingement } \\
\text { boiling }\end{array}$ & $\begin{array}{l}\text { Copper nanowires } \\
\text { 3M BEC }\end{array}$ & $\begin{array}{c}2 \mu \mathrm{m} \\
150 \mu \mathrm{m}\end{array}$ & $<20 \mu \mathrm{m}$ & - \\
\hline McHale et al. [38] & HFE-7300 & $\begin{array}{l}25.4 \mathrm{~mm} \times 25.4 \mathrm{~mm} \text { flat, horizontally } \\
\text { oriented copper substrate }\end{array}$ & Saturated pool boiling & $\begin{array}{l}\text { Metallized CNT } \\
\text { Sintered copper particles } \\
\text { Sintered copper particles and metallized CNT }\end{array}$ & - & $90-106 \mu \mathrm{m}$ & 65 \\
\hline Ammerman and You [28] & FC-87 & $\begin{array}{l}\text { Heated bottom wall of a } 2 \mathrm{~mm} \text { square } \\
\text { cross section channel }\end{array}$ & Subcooled flow boiling & $\begin{array}{l}\text { Paintable porous coating } \\
\text { (diamond particles) }\end{array}$ & $100 \mu \mathrm{m}$ & $8-12 \mu \mathrm{m}$ & - \\
\hline Rainey et al. [29] & FC-72 & $\begin{array}{l}10 \mathrm{~mm} \times 10 \mathrm{~mm} \text { horizontally oriented } \\
\text { heater in the bottom of a } 12.7 \mathrm{~mm} \\
\text { square cross section channel }\end{array}$ & Subcooled flow boiling & $\begin{array}{l}\text { Paintable porous coating } \\
\text { (aluminum particles) }\end{array}$ & $50 \mu \mathrm{m}$ & $<20 \mu \mathrm{m}$ & - \\
\hline Rainey and You [39] & FC-72 & $\begin{array}{l}10 \mathrm{~mm} \times 10 \mathrm{~mm} \text { horizontally oriented } \\
\text { copper substrate }\end{array}$ & Saturated pool boiling & $\begin{array}{l}\text { Finned copper blocks with paintable } \\
\text { porous coating (aluminum particles) }\end{array}$ & $\begin{array}{l}1-8 \mathrm{~mm} \text { fins } \\
50 \mu \mathrm{m} \text {-thick } \\
\text { coating }\end{array}$ & $<20 \mu \mathrm{m}$ & - \\
\hline Lay and Dhir [40] & $\begin{array}{l}\text { Water, } \\
\text { Freon-113 }\end{array}$ & $\begin{array}{l}17.6 \mathrm{~mm} \text { diameter flat, vertically } \\
\text { oriented copper substrate }\end{array}$ & $\begin{array}{l}\text { Subcooled jet impingement } \\
\text { boiling }\end{array}$ & $\begin{array}{l}\text { Finned copper surfaces with flame } \\
\text { sprayed copper particles }\end{array}$ & $\begin{array}{l}0.6-2 \mathrm{~mm} \text { fins, } \\
0.4 \text { mm-thick } \\
\text { coating }\end{array}$ & $60 \mu \mathrm{m}$ & 70 \\
\hline
\end{tabular}


with 3M's boiling enhancement coating (BEC) [19]. The coating was found to provide the greatest enhancement in heat transfer coefficient of up to $500 \%$ over a polished copper surface in pool boiling, as well as a 7\% to $20 \%$ enhancement of CHF in both pool and spray impingement boiling. In a study of porosity on boiling enhancement from dendritic copper surfaces, rather than particle-based coatings, El-Genk and Ali [20] found that the surface with the largest porosity produced the lowest nucleate boiling wall superheat.

Besides the metallic coatings considered above, paintable porous coatings that use an epoxy binder were investigated by You and coworkers [21-27]. O'Connor and You [22] created a paintable coating that consisted of 3-10 $\mu \mathrm{m}$ silver flakes, Omegabond 101 thermal epoxy, and isopropyl alcohol. The porous layer enhanced the nucleate boiling heat transfer coefficient by four times while also doubling CHF when compared to an untreated surface. Chang and You [23] studied five particle sizes (2, 10, 20, 45 , and $70 \mu \mathrm{m})$ with this paintable coating, and found a decreased temperature overshoot at the OND and an increased CHF with increasing particle size over the range investigated. Chang and You [24] found the boiling enhancement to be largely insensitive to the material composition of the coating, but instead dependent on the size and density of active pores created by the coating microstructure. A comparison to the commercially available High Flux metallic coating revealed benefits to more conductive coatings, as the High Flux coating performed equally well or better than the nonconductive coatings studied. A similar conclusion was drawn when comparing a paintable coating with aluminum particles to the High Flux coating on cylindrical surfaces [25]. These comparisons reveal that metallic coatings (e.g., sintered particles) are expected to provide superior heat transfer benefits relative to paintable coatings that suggest their use despite the more elaborate fabrication processes typically involved with metallic coatings. The increased conduction resistance of the nonconductive coatings was shown to have a greater detrimental effect in flow boiling situations in Refs. [28] and [29]. These studies investigated paintable porous coatings in a flow channel and concluded that the reduced slope in the boiling curve compared to the uncoated surface was a result of increased conduction resistance of the microporous coating.

The use of extended surfaces to increase surface area offers an alternative to nucleation site promoters for augmenting heat transfer. Fin structures have been explored for boiling heat transfer enhancement in pool boiling and two-phase jet impingement [30,31]. Anderson and Mudawar [32] investigated pool boiling of FC-72 on longitudinal fins and pin fins (both $0.508 \mathrm{~mm}$ tall), and found both to reduce boiling superheat and extend CHF. Guglielmini et al. [33] experimentally studied the effect of pin fin width, length, and spacing on pool boiling of FC-72. Dense arrays of thin fins (providing the most surface area) yielded the best nucleate boiling performance, while long fins provided the most enhancement in CHF. In a study of pool boiling of HFE-7100, with large $3 \mathrm{~mm} \times 3 \mathrm{~mm}$ pin fins located at the corners of their $10 \mathrm{~mm} \times 10 \mathrm{~mm}$ heat source, Parker and El-Genk [34] found that the tallest fins investigated ( $5 \mathrm{~mm}$ height) not only had the highest total heat transfer rate but also provided a significant $\mathrm{CHF}$ enhancement for a horizontal surface in a downward-facing orientation, mitigating some of the effects of vapor blanketing.

Besides overall area enhancement, the ready supply of liquid to the fin array and efficient vapor removal is critical to achieving high heat fluxes. By studying the effect of pin-fin spacing on pool boiling of water and R-113, Klein and Westwater [35] showed that individual fins within an array would perform identically to single, isolated fins provided the spacing was sufficiently wide enough to prevent vapor clogging between fins in the array. $\mathrm{Yu}$ and $\mathrm{Lu}$ [36] obtained photographs of FC-72 boiling from $1 \mathrm{~mm} \times 1 \mathrm{~mm}$ pin fins of different heights and spacings. They observed vapor bubble coalescence between fins that may have prevented liquid from rewetting the inner surfaces, an effect that was exacerbated with tight fin-fin spacing. Wei and Honda [37] studied saturated and subcooled pool boiling of FC-72 on square microscale pin fins etched into silicon test surfaces. Multiple surfaces were fabricated with fin thicknesses of $30 \mu \mathrm{m}$ or $50 \mu \mathrm{m}$ (with a pitch equal to double the fin thickness) and heights ranging from 60 to $270 \mu \mathrm{m}$. The CHF was observed to increase with increasing surface area. At constant total wetted surface area, surfaces with the largest gaps between fins yielded the highest $\mathrm{CHF}$, an observation they attributed to the additional space for vapor to escape and liquid to rewet the surface between fins.

Hybrid surfaces created from combining extended structures of different scales (e.g., macroscale extended surfaces with microporous coatings) can display synergistic advantages that provide enhancements greater than those of the individual approaches. McHale et al. [38] investigated pool boiling enhancement due to hybrid micro-nano surface structures in HFE-7300. Carbon nanotubes grown on top of a sintered-copper porous coating yielded enhancements that represented a combination of those observed for the individual structures. Chang and You [25] found that combining a microporous coating with low, triangular-shaped machined fins resulted in slightly better performance than just the bare fin or the coated flat surfaces alone. The coated fins, however, displayed a slightly lower CHF than the uncoated finned surface; this was attributed to vapor entrapment in the microporous coating between fins. An effective vapor-bubble removal mechanism was said to be necessary to take full advantage of this combined macro/micro-enhancement technique. In a study of the effect of fin length for pin fins coated with a thin microporous coating, Rainey and You [39] found that increasing the fin height continuously enhanced CHF, although only small additional gains were realized for fin lengths greater than $5 \mathrm{~mm}$ due to low fin efficiencies.

Lay and Dhir [40] characterized the two-phase cooling capabilities of an impinging jet on a variety of macro/microscale surface structures formed by fins, ribs, and flame-sprayed copper coatings. The hybrid surfaces outperformed each individual surface enhancement, and the surface yielding the best liquid distribution and bubble evacuation characteristics, along with the greatest enhancement in nucleation site density, provided the best overall performance.

While the extensive literature on boiling surface enhancements highlights the potential benefits from enhanced surfaces for twophase cooling systems, the sometimes inconsistent results also show that the enhancement mechanisms involved in designing structured surfaces need to be better understood. Hybrid enhancement structures utilizing macroscale extended surfaces with highly conductive microporous coatings, combined with impinging flow conditions, show promise as a means to augment heat transfer rates and extend the safe operating range of two-phase cooling devices, especially with active vapor evacuation strategies. The enhancement of the cooling performance of a single impinging liquid jet (and a $5 \times 5$ array of jets presented in a companion paper [41]) of HFE-7100 dielectric liquid using a variety of surface enhancements is characterized in the present work. To delineate the effects of each aspect of the hybrid enhancement approach, the two-phase heat transfer and pressure drop are measured for four different surfaces: a baseline smooth flat surface, a flat surface coated with a microporous layer, a surface with macroscale area enhancement (extended square pin fins), and a hybrid surface on which the pin fins are coated with the microporous layer.

\section{Experimental Setup}

2.1 Flow Loop. The flow loop used for this experimental investigation is the same as in a previous study by the authors [3]. Complete details are provided in the original reference, while essential details are outlined here for completeness. A schematic diagram of the flow loop is shown in Fig. 1. A magnetically coupled gear pump circulates HFE-7100 $\left(k_{1}=0.069 \mathrm{~W} / \mathrm{mK}\right.$, 


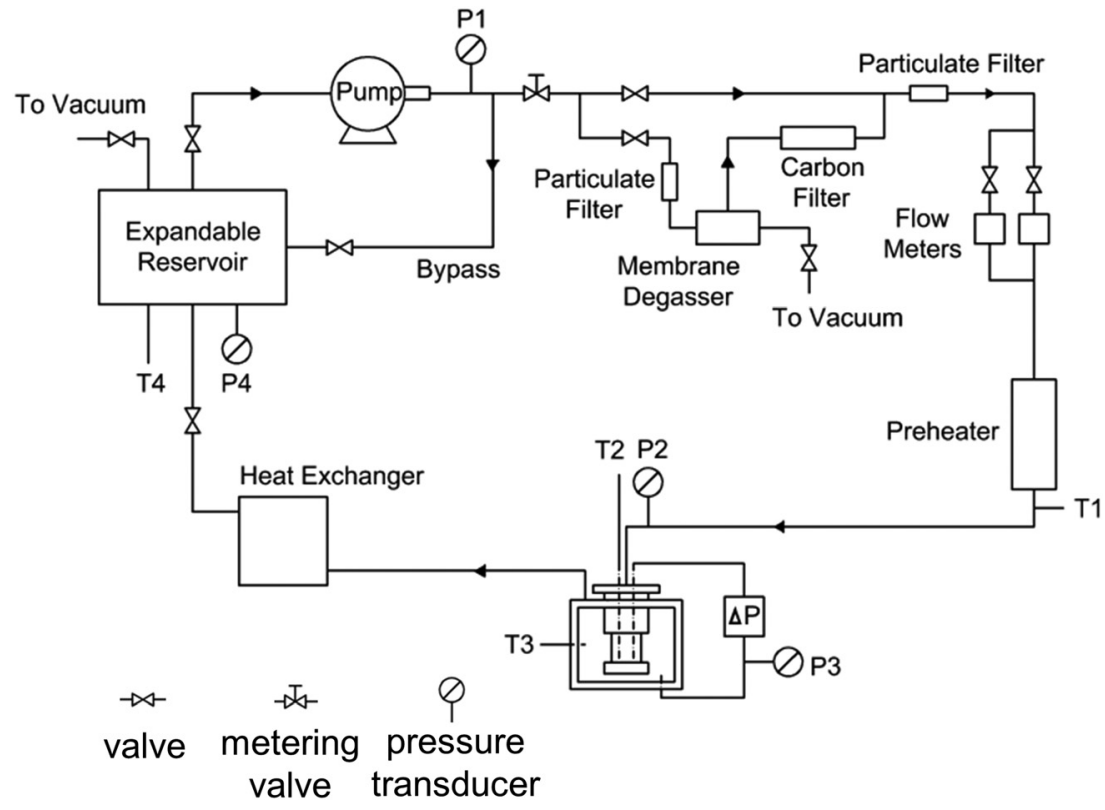

Fig. 1 Flow loop schematic diagram

$\rho=1481 \mathrm{~kg} / \mathrm{m}^{3}, c_{\mathrm{p}}=1183 \mathrm{~J} / \mathrm{kgK}, \mu=5.63 \times 10^{-4} \mathrm{~kg} / \mathrm{ms}$ at $25^{\circ} \mathrm{C}$, $T_{\text {sat }}=61^{\circ} \mathrm{C}$ at atmospheric pressure [42]) through the flow loop. A $40 \mu \mathrm{m}$ particulate filter mounted in series with the flow loop and a carbon filter are used to ensure fluid cleanliness. The use of silicone rubbers and other fluorinated materials in the facility is avoided to the extent possible to prevent leaching of contaminants into the fluid.

The flow loop is instrumented with two turbine flowmeters (S-114, McMillian) with ranges of $100-1000 \mathrm{ml} / \mathrm{min}$ and $500-5000 \mathrm{ml} / \mathrm{min}$ to measure the volumetric flow rate, which is finely controlled by a metering valve. A temperature-controlled inline heater controls the fluid inlet temperature, while a liquid-toair heat exchanger cools the fluid as it is returned to the reservoir. An expandable reservoir aids fluid degassing and controls operating pressure. The reservoir design, presented in detail in Ref. [43], can only effectively degas the volume of fluid contained within the reservoir at a given time. Due to the large amount of liquid residing outside of the reservoir in the current experimental facility ( $\sim 2 / 3$ of the total fluid volume is contained within the facility piping and test section), this degassing method was supplemented with a membrane contactor (SuperPhobic, Membrana) included in the same bypass loop as the carbon filter to speed up the degassing process. The contactor consists of a superhydrophobic porous membrane that allows vacuum to be pulled on the liquid as it continuously flows through the flow loop, drawing air, and other entrapped gases out of the liquid through the pores in the membrane. This model of contactor was designed specifically for use with low-surface-tension liquids that are highly wetting, as is the case with the working fluid HFE-7100. The fluid is filtered of particulates larger than $7 \mu \mathrm{m}$ in the bypass loop to avoid clogging of the small pores in the membrane.

2.2 Test Section. The confined and submerged jet impingement test section is shown in Fig. 2. It accommodates testing over a wide range of jet impingement parameters, viz., different orifice geometries, orifice-to-target spacing, and target surface geometries. The test section design was originally presented in Ref. [3], and has been modified for the present study to accommodate a copper block heat source. The test section components are made from polyether ether ketone (PEEK) and polycarbonate to minimize heat losses and provide optical access. Liquid enters the test section through the top of a cylindrical jet plenum, and uniform flow is ensured by the use of three flow conditioners. Jets are formed as liquid is forced through the sharp-edged orifices in the orifice plate at the bottom of the plenum. After impingement, the fluid outflow is confined between the orifice plate (above) and target surface (below) and flows radially outward into the test chamber. The fluid ultimately exits the test section through the single outlet located at the top of the chamber. The plenum height is adjustable relative to the test section body and is sealed by a translating o-ring around its outer diameter. The orifice-to-target spacing is fixed for each test case through the use of three precision-machined stainless steel spacing pins.

The plenum is instrumented with a T-type thermocouple and a $1.6 \mathrm{~mm}$ diameter pressure tap located just upstream of the jet orifice plate as shown in Fig. 2. The test section chamber is instrumented with an additional T-type thermocouple and pressure tap. A differential pressure transducer (PX2300-2DI, Omega) with a $0-13.8 \mathrm{kPa}$ range measures the pressure difference between the two pressure taps, while a gauge pressure transducer with a $0-103 \mathrm{kPa}$ range (PX302-015GV) records the pressure within the test chamber. All pressure transducers are precisely calibrated (Pascal 100, Scandura), with resulting uncertainties of $\pm 0.01 \mathrm{kPa}$ for the differential transducer and $\pm 0.13 \mathrm{kPa}$ for the gauge

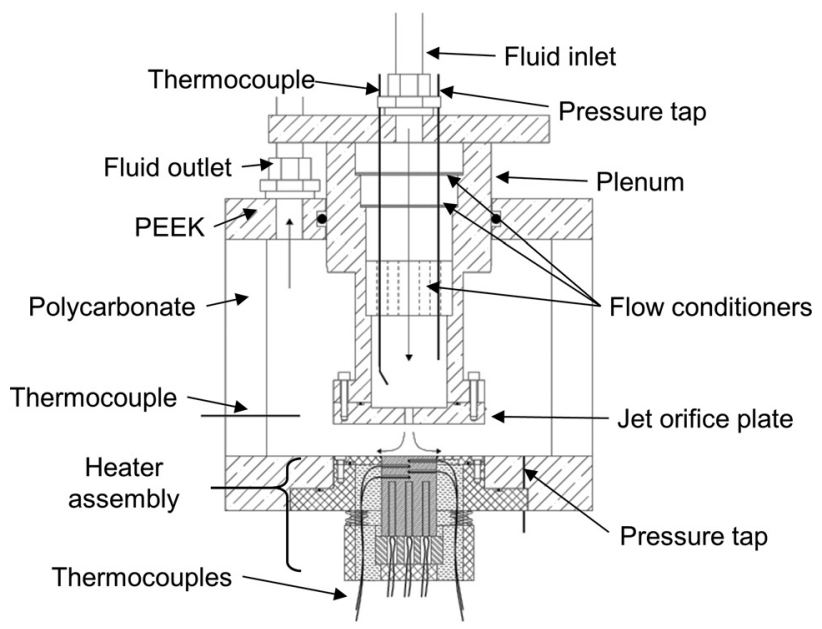

Fig. 2 Cross-sectional illustration of the jet impingement test section with copper heat source installed 
pressure transducer. The location of the thermocouples and pressure taps are included in Fig. 2.

2.3 Copper Block Heat Source. In a previous study by the authors [3], localized heat transfer distributions were obtained on the surface of an electrically heated thin-foil heat source stretched taut between bus bars. For the present work, a copper block heater is used as the heat source to allow for integration of the enhanced surfaces. The heater block, as shown in Fig. 2, is machined from oxygen-free copper and provides a $25.4 \mathrm{~mm} \times 25.4 \mathrm{~mm}$ wetted impingement surface area. Heat is generated by twelve 1 in. (25.4 $\mathrm{mm}$ ) long, $36 \Omega$ cartridge heaters embedded in the block. Four thermocouple taps are spaced $2.54 \mathrm{~mm}$ apart vertically along the centerline of the block for insertion of $0.8 \mathrm{~mm}$ diameter T-type sheathed thermocouples. The rake of thermocouples at the center point of the block allows calculation of the temperature gradient. All thermocouples are calibrated prior to installation using a highuniformity oil temperature bath (7103 Micro-Bath, FLUKE), and are referenced to a dry-block ice-point chamber (TRCIII, Omega). The uncertainty in thermocouple measurements is estimated to be $0.3{ }^{\circ} \mathrm{C}$. Extrapolation to calculate the surface temperature of the heating block results in an uncertainty of $0.4^{\circ} \mathrm{C}$ at low heat fluxes and approximately $0.8^{\circ} \mathrm{C}$ at a heat flux of $88 \mathrm{~W} / \mathrm{cm}^{2}$.

The copper heating block and surrounding insulation assembly are shown in Fig. 3. The block is supported from below by a square piece of ceramic insulation (Rescor $310 \mathrm{M}$, Cotronics) held in place by a supporting PEEK carrier. The carrier is mounted to a surrounding circular adapter that allows the heater assembly to be installed in the jet impingement test section. Once the heating block is positioned on the ceramic support, the sheathed thermocouples are fed through the bottom of the assembly and inserted into the thermocouple taps in the copper block. The void around the heating block is then packed with loose-fill fiberglass insulation and the assembly is capped by a 4-mm-thick PEEK plate that fits tightly around the square copper block. The capping plate is sealed to the rest of the assembly with an o-ring. A 1-mm-wide chamfer along the interior square hole in the capping plate creates a thin groove around the top edge of the heating block for sealing. To account for machining and assembly tolerances, the carrier is mounted to the circular adapter with four spring-loaded screws to allow for adjustability in the final assembly. These screws can be

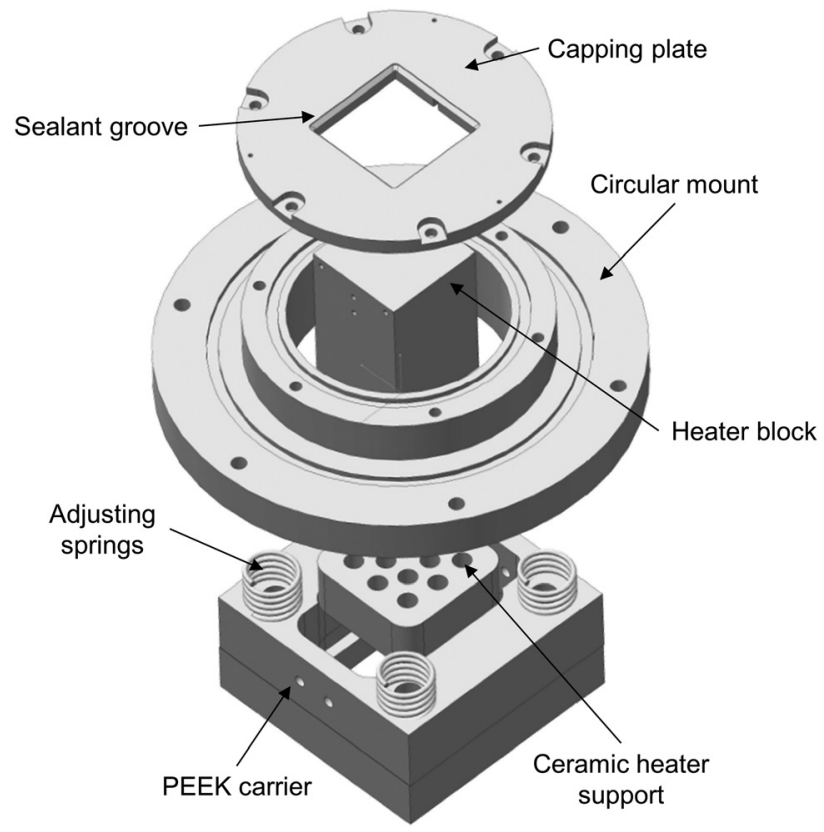

Fig. 3 Exploded view of the heater assembly (hardware, seals, and loose-fill fiberglass insulation not shown) finely adjusted to set the copper block perfectly flush with the top edge of the capping plate to avoid disruption of the impinging flow. Once positioned, the heater block is sealed by filling the groove in the capping plate with a thin bead of silicone sealant (3-6265, Dow Corning). Great care is taken during sealing to ensure that the resulting silicone bead is smooth and flush with the upper edges of the copper block and surrounding PEEK capping plate. The sealant is cured in an oven and the assembly is installed in the test section described in Sec. 2.2.

The cartridge heaters are inserted through the carrier and ceramic insulation into the bottom of the copper heating block. Electrical power to the cartridge heaters is supplied by a DC power supply. The total electrical power supplied is calculated from the voltage drop across all twelve heaters wired in parallel, and the electrical current measured using a $1.667 \mathrm{~m} \Omega$ shunt resistor.

2.4 Surface Enhancements. To investigate the effects of different surface enhancement structures on the two-phase heat transfer under a confined and submerged impinging jet, three distinct enhanced surfaces are fabricated on the top surface of the copper block heaters for comparison to a baseline smooth copper surface. The surface enhancement strategies include coating the flat surface with a microporous layer, inclusion of macroscale area enhancement (extended square pin fins) on the flat surface, and implementing a hybrid approach with the pin fins being coated with the microporous layer. These surfaces are shown in Figs. 4(b)-4(e).

The pin fins are CNC-machined into the top of the copper heater block so that the fin base surface corresponds to the top surface of a smooth block. The $0.5 \mathrm{~mm} \times 0.5 \mathrm{~mm}$ fins are $2.5 \mathrm{~mm}$ tall and in an orthogonal array with a pitch of $1.5 \mathrm{~mm}$, as shown in

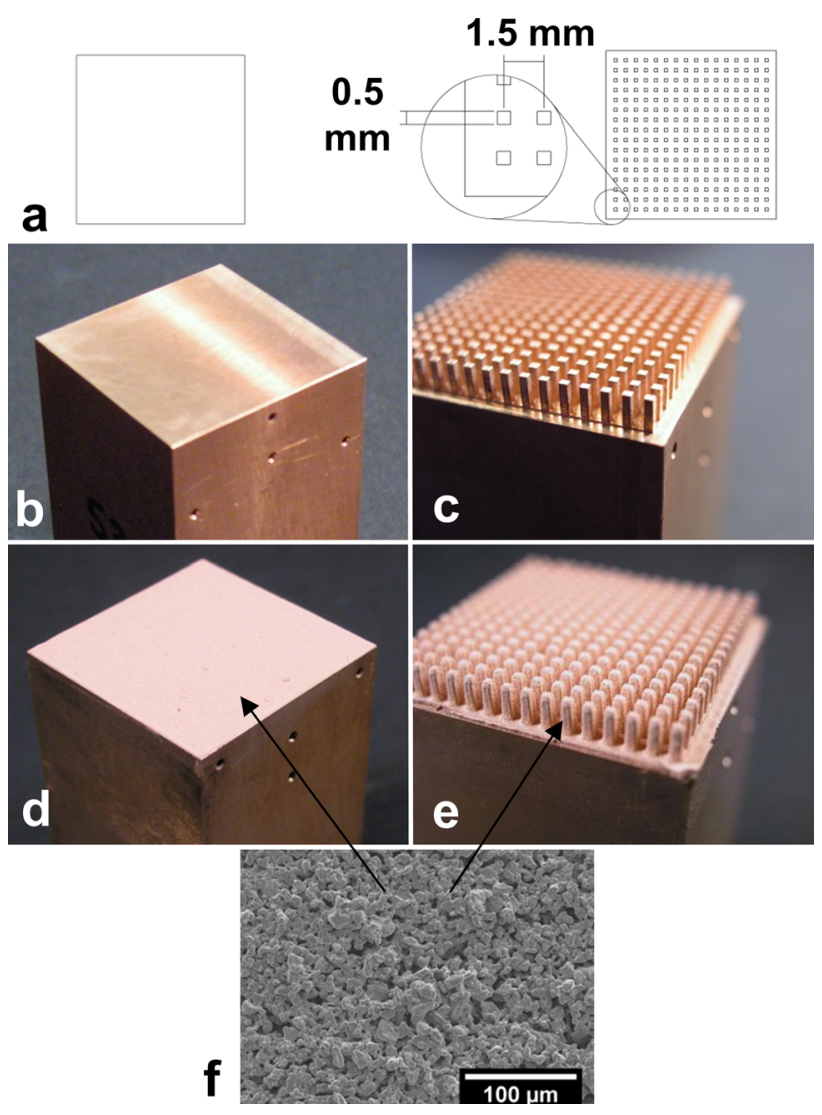

Fig. 4 (a) Illustration of the surface designs, and photographs of the $(b)$ baseline smooth surface, $(c)$ uncoated pin fins, (d) coated flat surface, $(e)$ coated pin fins, and $(f)$ SEM image of the microporous coating 
Fig. 4(a). The fins are designed to provide significant (threefold) area enhancement over the baseline surface while still maintaining sufficient spacing between neighboring fins to allow the application of the metallic porous coating on the fin base, side, and top surfaces. The baseline and finned surface finishes are left in their as-machined condition. Both surfaces are characterized using an interferometric optical profiling system (NewView 7300, Zygo) and display similar surface roughness $\left(R_{\mathrm{a}} \approx 0.5-0.7 \mu \mathrm{m}\right)$.

Multiple microporous coatings were considered, as the ability to apply the coating conformally to fin structures was critical. Paintable coatings [21-29,39] and flame-sprayed coatings were both considered: paintable coatings were avoided due to their low effective thermal conductivity. Ultimately, the $3 \mathrm{M}$ Boiling Enhancement Coating [19] was chosen for its many advantages, including the ability to be fused to three-dimensional (3D) surface features without any applied pressure. The coating consists of sub-20 $\mu \mathrm{m}$ diameter copper particles and is applied as an approximately $150 \mu \mathrm{m}$-thick layer. Investigation of this coating has been limited in the literature to pool boiling $[44,45]$ and spray impingement boiling [18]. For the current investigation, the coating was applied by $3 \mathrm{M}$ as an oil-particle mixture to all wetted surfaces of a flat and pin-finned block (Figs. 4(d) and 4(e)). The applied coating was then fired in-house at a temperature of $850^{\circ} \mathrm{C}$ for $1 \mathrm{~h}$, while maintaining a vacuum pressure of 5 mTorr. A slow temperature ramp (approximately $50^{\circ} \mathrm{C} / \mathrm{h}$ ) was used while traversing the boiling point of the oil mixed with the particles to facilitate gentle evaporation of the oil from within the particle layer, as rapid evaporation or bubble formation could damage the unfired coating. The porosity of the coating powder prior to firing was estimated by weight and volume to be approximately 58\%. An SEM image of the coating is shown in Fig. $4(f)$.

2.5 Experimental Procedures. After the copper block heating assembly, orifice plate, and spacing pins are installed in the test section, the test chamber is sealed and the flow loop degassed. The test fluid, HFE-7100, must be degassed prior to running a two-phase heat transfer experiment because of its high affinity for absorbing air (solubility of up to $53 \%$ by volume at $1 \mathrm{~atm}$ [42]). The fluid is degassed by running the liquid at a flow rate of $500 \mathrm{ml} / \mathrm{min}$ through the membrane contactor while applying vacuum to the nonwetted side of the device. The liquid is degassed continuously until the saturation temperature of the liquid is in agreement with properties provided by the manufacturer, as measured in the expandable reservoir.

While it is well-known that dissolved gases in the liquid can alter the boiling characteristics of a liquid, it is also important to free the surface microstructure of entrapped gases, as they may affect the incipience superheat experienced at ONB. Anderson and Mudawar [32] investigated the effect of nonboiling time between vigorously boiling a polished copper surface in FC-72 and running an incipience overshoot experiment. Increasing the waiting time from 8 to $72 \mathrm{~h}$ increased the incipience overshoot at ONB, indicating that the collapse of vapor embryos trapped on the surface after boiling is terminated occurs over a prolonged period of time. Marto and Lepere [17] investigated four different surface preparation procedures for their influence on incipience overshoot from enhanced boiling surfaces in FC-72: (1) boiled and allowed to cool to ambient overnight in a pool of liquid, (2) boiled and then allowed to cool for $30 \mathrm{~min}$, (3) boiled and immediately tested, and (4) air-dried at $65^{\circ} \mathrm{C}$ for $10 \mathrm{~min}$ and immediately tested. The surface allowed to cool overnight always resulted in the largest temperature excursion, and this was explained by the maximum number of nucleation cavities being flooded by this preparation method. In the present work, the four surfaces were consistently prepared by vigorously boiling in degassed liquid and then allowed to fully cool to room temperature prior to testing (approximately $12-14 \mathrm{~h}$ ) while immersed in the test liquid.

After the fluid and surface are degassed using the procedures outlined above, the fluid is circulated through the flow loop at a constant flow rate, and an inlet subcooling of $10^{\circ} \mathrm{C}$ is maintained using the inline heater. The fluid saturation temperature at the test section is calculated based on the measured chamber pressure. The reservoir is initially maintained at a slightly positive pressure (approximately $20 \mathrm{kPa}$ above atmospheric) to provide room for pressure relief during testing. As the pressure in the test section increases with increased heat input during testing (due to thermal expansion of the working fluid and increased two-phase pressure drop in the flow lines) the additional pressure is relieved by slowly expanding the reservoir to maintain constant pressure (and therefore constant saturation temperature) operation. Once the desired flow rate and inlet temperature are achieved, the cartridge heaters are powered up to the desired heat input. Power is then incremented after collecting steady-state data (averaged over $4 \mathrm{~min}$ ) at each desired heat flux.

At the cartridge heater power increment that causes the ONB, a significant and sudden reduction in the surface temperature of the block is measured. To estimate the heat flux and surface temperature at $\mathrm{ONB}$, the transient data just prior to the incipience event (corresponding to a surface temperature within $0.5^{\circ} \mathrm{C}$ of the incipience event) are averaged; the time over which data are averaged ranged from a few seconds to $4 \mathrm{~min}$, depending on the immediacy of the ONB occurrence after the increase in heater power following the previous steady-state data point. This disparity in the number of averaged data points results in slightly higher uncertainty in the incipience temperature $\left(0.5^{\circ} \mathrm{C}-0.6^{\circ} \mathrm{C}\right)$ than for steady-state surface temperatures at similar heat fluxes $\left(0.4^{\circ} \mathrm{C}\right)$.

Testing is concluded once CHF is reached, which is characterized by a sudden and sustained rate of surface temperature rise of greater than $1{ }^{\circ} \mathrm{C} / \mathrm{s}$ following a small increment in heater power. The large copper block heat source used in this study provides significant thermal mass, yielding a relatively slow CHF temperature excursion (on the order of a few seconds). This slow response allows CHF to be safely reached without causing damage to the block or heating elements. The CHF values reported in this work are obtained from the transient temperature response of the heating block (similar to the ONB determination) when the CHF transition upon incrementing the power is not immediate. For immediate transitions, CHF is taken as the last steady-state heat flux achieved by each experiment.

The boiling performance of all four surfaces is characterized under a single confined and submerged impinging jet. This orifice has a diameter, $d$, of $3.75 \mathrm{~mm}$, a dimensionless length, $l / d$, of 2 , and a dimensionless orifice-to-target spacing, $H / d$, of 4 , which implies a $15 \mathrm{~mm}$ gap between the heated surface and confining orifice plate. The experiments are conducted at three flow rates, 450,900 , and $1800 \mathrm{ml} / \mathrm{min}$, corresponding to Reynolds numbers of $9600,19,200$, and 38,900 , respectively.

2.6 Data Reduction. The temperature gradient in the copper block heater is obtained based on measurements with the thermocouple rake located along the centerline. The surface temperature, $T$, is then extrapolated assuming one-dimensional conduction in the block. The heat flux to the fluid is obtained by a heat loss analysis. Heat lost from the copper block heater is estimated numerically using a 3D conduction model in FLUENT [46] in the same manner as outlined in Ref. [47]. The copper block $(k=391 \mathrm{~W} / \mathrm{mK}$, with a region of uniform heat generation representing the cartridge heaters), PEEK $(k=0.25 \mathrm{~W} / \mathrm{mK})$, ceramic $(k=0.346 \mathrm{~W} / \mathrm{mK})$, and fiberglass $(k=0.06 \mathrm{~W} / \mathrm{mK})$ insulation are all included in the model. The material properties are obtained from the manufacturers, except for the loose-fill fiberglass insulation, where the thermal conductivity is estimated from Ref. [48] and found to agree with similar values in the literature. Natural convection boundary conditions $\left(h_{\text {nat }}=10 \mathrm{~W} / \mathrm{m}^{2} \mathrm{~K}\right.$ is used to estimate heat loss to the ambient), the measured electrical heat generation, and the block surface temperature are set as boundary conditions in the model, and the resulting heat losses to the ambient are calculated for each experimental steady-state heat flux. 


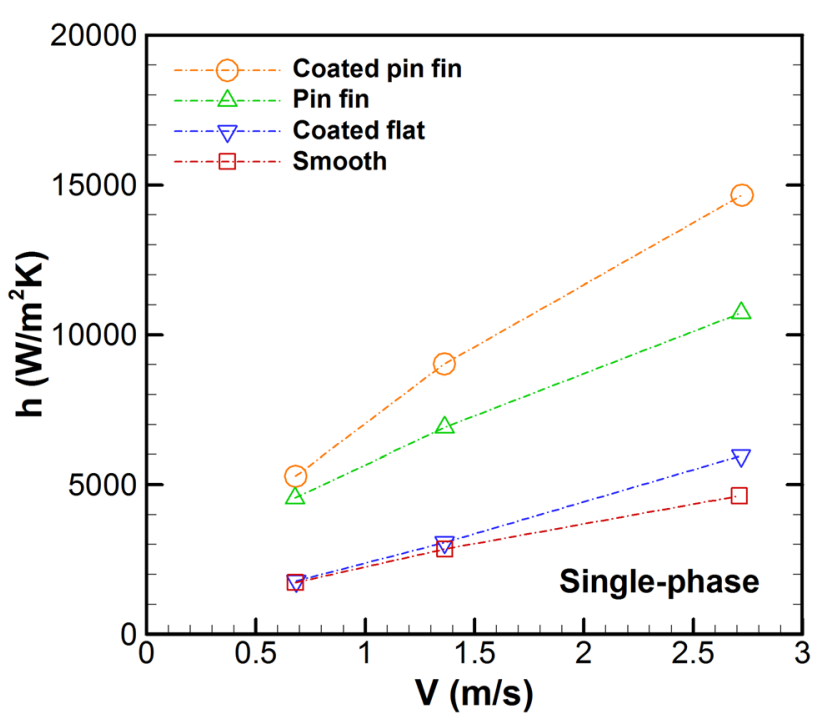

Fig. 5 Area-averaged single-phase heat transfer coefficient plotted as a function of jet velocity for all four surfaces at the heat flux just prior to the onset of boiling

The heat loss contribution of the 24 wire leads attached to the cartridge heaters is also estimated assuming that they act as infinitely long fins. The total heat loss, $q_{\text {loss }}$, is found to range from $20 \%$ at low heat fluxes to approximately $2 \%$ at nucleate boiling heat fluxes on the highest performing surfaces.

With the heat losses known, the area-averaged heat flux transferred to the fluid through the test surface, $q^{\prime \prime}$, can be calculated according to

$$
q^{\prime \prime}=\frac{P-q_{\mathrm{loss}}}{A_{\mathrm{b}}}
$$

where $P$ is the total electrical power dissipated by the cartridge heaters, $q_{\text {loss }}$ is the estimated total heat loss, and $A_{\mathrm{b}}$ is the surface area of the top of the smooth copper heater block. The copper block heat source used does not allow a determination of local heat fluxes. The effective surface efficiency for the pin-fin surfaces is calculated according to Ref. [48]

$$
\eta_{\mathrm{o}}=1-\frac{N A_{\mathrm{f}}}{A_{\mathrm{t}}}\left(1-\eta_{\mathrm{f}}\right)=\frac{q^{\prime \prime} A_{\mathrm{b}}}{h_{\mathrm{eff}} A_{\mathrm{t}} \Delta T_{\mathrm{b}}}
$$

where $N$ is the total number of fins, $A_{\mathrm{t}}$ is the total wetted surface area, $A_{\mathrm{f}}$ is the surface area of one fin assuming an active tip, and $\Delta T_{\mathrm{b}}$ is the temperature difference at the base of the fin $\left(T-T_{j}\right)$. The effective fin efficiency $\eta_{\mathrm{f}}$ is given by

$$
\eta_{\mathrm{f}}=\frac{\tanh \left(m L_{\mathrm{c}}\right)}{m L_{\mathrm{c}}}
$$

where $m=\sqrt{4 h_{\mathrm{eff}} / k_{\mathrm{f}} w}$, and the corrected fin length is $L_{\mathrm{c}}=L+w / 4$. Equations (2) and (3) are iteratively solved to calculate the overall surface efficiency $\left(\eta_{\mathrm{o}}\right)$. Although this calculation utilizes the simplifying assumption that the fins experience a constant effective heat transfer coefficient, $h_{\text {eff }}$, on their side and base surfaces, the effective surface efficiency is still a valuable tool for evaluating the chosen fin designs. Similar comparisons have been used in the literature [39].

The average heat transfer coefficient is defined based on the jet inlet temperature, as is typical in the two-phase jet impingement literature

$$
h=\frac{q^{\prime \prime}}{\left(T-T_{\mathrm{j}}\right)}
$$
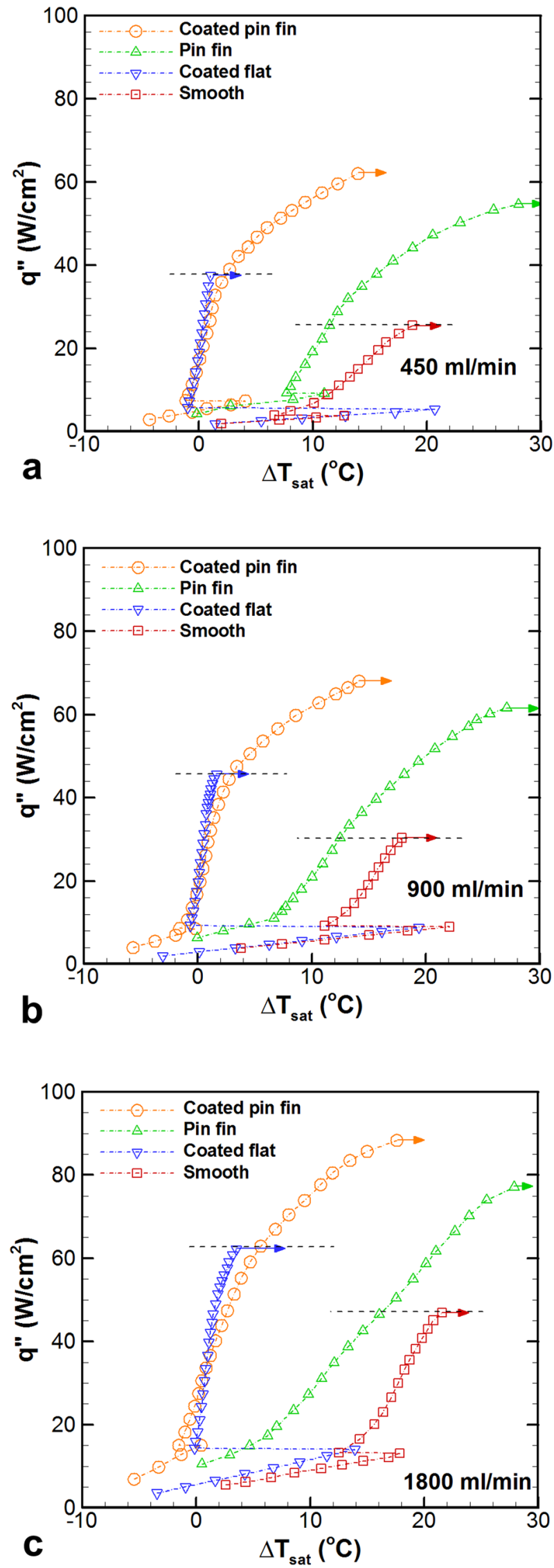

Fig. 6 Boiling curves for all surface enhancements at a flow rate of (a) $450 \mathrm{ml} / \mathrm{min}$, (b) $900 \mathrm{ml} / \mathrm{min}$, and (c) $1800 \mathrm{ml} / \mathrm{min}$; arrows indicate $\mathrm{CHF}$ 
where $T$ is the surface temperature of the block and $T_{\mathrm{j}}$ is the jet inlet temperature.

Through a standard uncertainty analysis [49], the uncertainty in heat flux is estimated to be less than $2 \%$ using a $95 \%$ confidence interval. The estimate includes the uncertainty contributions from the heating block surface temperature, $T$, and the power dissipated by the cartridge heaters, $P$, as heat losses calculated in FLUENT were found to be a strong function of these two inputs. The uncertainty in the area-averaged convection coefficient is found to range from $11 \%$ at low heat fluxes to $3 \%$ at high heat fluxes.

\section{Results and Discussion}

3.1 Effect of Surface Enhancement. While the surface features investigated are designed for enhanced boiling heat transfer, their performance under single-phase operation is also of interest and can shed light on the enhancement mechanisms at play. Figure 5 shows the area-averaged, single-phase heat transfer coefficient as a function of jet velocity for each enhancement type. In the figure, the average heat transfer coefficient on the baseline, smooth surface increases with increasing jet velocity. The coated flat surface yields the same heat transfer coefficient at the lowest jet velocity $(0.68 \mathrm{~m} / \mathrm{s})$, but a slightly higher cooling performance than the smooth surface at higher velocities ( 1.36 and $2.71 \mathrm{~m} / \mathrm{s})$. It is clear that the coating does not add significant thermal resistance compared to the uncoated baseline surface, as might be expected due to the minimal coating thickness, good particle-to-particle adhesion, and high intrinsic conductivity. The coating also does not appear to provide an effective surface area enhancement. The increased convective cooling provided by the coated surface at high jet velocities is likely caused by increased wall-jet boundary layer turbulence induced by the roughness of the surface coating. Moreno et al. [50] observed similar trends using the same microporous coating under a submerged impinging jet of water, and attributed the single-phase enhancement at high jet Reynolds numbers to an acceleration of the transition to turbulence.

The addition of pin fins, as expected, provides significant enhancement in single-phase heat transfer, indicated by their noticeable offset from the smooth surface. The fins augment the heat transfer coefficient by 2.32-2.64 times, as a result of their high surface efficiency. Interestingly, the coated pin fins seem to further enhance the single-phase heat transfer compared to the plain pin fins; enhancement is slight at the lowest jet velocity and large at the highest jet velocity. The porous conformal coating creates approximately a $40 \%$ increase in surface area for a uniform $150 \mu \mathrm{m}$-thick coating on all exposed areas of the fins (assuming the microstructure of the coating does not contribute any area enhancement). The added area, combined with the negligible conduction resistance offered by the coating, contributes to the 1.16 times enhancement in heat transfer coefficient over the uncoated pin fins observed at the lowest jet velocity. The increase in enhancement with increasing jet velocity is likely caused by higher fluid velocities between the fins (the gap between fins is reduced with the addition of the conformal coating), as well as the turbulence effects discussed earlier.

Figure 6 shows the boiling curves at each flow rate for all four surfaces. The boiling curves presented reference the fluid saturation temperature, $T_{\text {sat }}$. The baseline surface is the smooth flat, as-machined copper surface, and presents a typical two-phase impingement boiling curve at all flow rates. A modest incipience overshoot $\left(5-11^{\circ} \mathrm{C}\right)$ at the onset of boiling is followed by a slope increase as the heat transfer from the surface becomes less influenced by the convective cooling of the liquid jet and is dominated by the nucleate boiling heat transfer. $\mathrm{CHF}$ for the baseline surface at the highest flow rate is $46.9 \mathrm{~W} / \mathrm{cm}^{2}$ (CHF for all surfaces and flow rates are summarized in Table 2). After the ONB on the uncoated pin-fin surface, the wall superheat is comparatively lower by $\sim 6-8{ }^{\circ} \mathrm{C}$. The pin fins greatly extend the operating range at all flow rates, more than doubling $\mathrm{CHF}$ at $450 \mathrm{ml} / \mathrm{min}$ and
$900 \mathrm{ml} / \mathrm{min}$. The leftward shift in the boiling curve for the pin-fin surface is characteristic of its increased surface area and increased number of nucleation sites.

The addition of the porous coating has a drastic effect on the two-phase heat transfer from the copper block, as illustrated at all flow rates in Fig. 6. Both the coated flat and coated pin-fin surfaces display a dramatic leftward shift in their nucleate boiling curves when compared to the uncoated surfaces. In both cases, much of the boiling heat transfer prior to CHF for the coated flat surface occurs within $3{ }^{\circ} \mathrm{C}$ of the saturation temperature of the fluid. The coated flat surface experiences an unexpectedly large incipience temperature overshoot at all flow rates (in excess of $20^{\circ} \mathrm{C}$ at $450 \mathrm{ml} / \mathrm{min}$ ) before displaying a nearly vertical boiling curve. The coated pin-fin surface, in contrast, experiences a lower overshoot at ONB in all cases.

The coated fins also outperform the coated flat surface just after $\mathrm{ONB}$, displaying lower wall superheats at the lowest heat fluxes for which boiling is observed. In the context of the single-phase operation discussed above, the higher relative performance is likely due to the dominance of convective transport in the overall heat dissipation on the finned surface at these heat fluxes. This difference would be expected to be largest at the highest jet velocity, as is indeed observed in Fig. 6. The coated flat and coated pin-fin surfaces display similar wall superheats in the nucleate boiling range. In contrast to the uncoated surfaces, where the addition of the pin fins creates more nucleation sites in addition to an increase in surface area, the porous coating alone provides a sufficient number of nucleation sites such that additional sites created by the pin fins do not lead to further decreases in wall superheat. No further boiling enhancement is provided by the coated pin fins compared to the coated flat surface once nucleate boiling is the dominant heat transfer mechanism. The coated pin-fin surface displays a slightly reduced slope compared to the coated flat surface, resulting in a cross-over of boiling curves between the coated flat and coated pin-fin surfaces. This reduced slope is caused by the added conduction resistance of the pin fins.

Conversely, the coated pin fins greatly extend CHF compared to the flat porous surface, resulting in an increase in CHF of between 1.42 and 1.65 times depending on the flow rate. Another advantage of the coated pin fins is that CHF is approached in a gradual manner (so that it may be pre-empted). As CHF is approached, the temperature of the base surface steadily increases as the overall heat transfer coefficient decreases. The very sudden dryout temperature excursion displayed by the coated flat surface, on the other hand, precludes surface-temperature based detection of impending dryout in realtime. The porous coating alone yields a significant increase in CHF on the flat surface (an increase of 1.32-1.51 times), but only a slight additional increase when applied to the pin-fin surfaces (an increase of 1.10-1.14 times). A comparison of the enhancement in $\mathrm{CHF}$ for each surface compared to the baseline surface is provided in Table 2 .

A comparison of the boiling curves obtained with the uncoated and coated pin-fin surfaces to their corresponding flat surfaces in Fig. 6 shows an interesting trend just after $\mathrm{CHF}$ is reached on the flat surfaces. At all flow rates, the boiling curves for the pin-fin and coated pin-fin surfaces display a marked reduction in slope at this heat flux. Given that this reduction coincides with CHF for the flat surfaces, this sudden reduction in performance is likely due to dryout at the base of the fins. A similar trend was observed by Rainey and You [39] for their plain and microporous-coated finned surfaces. The reduced performance was attributed to increased bubble departure resistance rather than dryout of the base surface. The relatively large orifice-to-target spacing used in the current study $(H / d=4)$ allows high-speed imaging of jet impingement and boiling on the surface enhancements through the side of the $15 \mathrm{~mm}$-tall confinement gap. The series of highspeed images shown in Fig. 7 support the theory that dryout of the base surface causes the change in slope at high heat fluxes. At heat fluxes below this transition, discrete bubbles can be observed 
Table 2 CHF for all surface enhancements considered at all flow rates

\begin{tabular}{llcc}
\hline \hline Flow rate $(\mathrm{ml} / \mathrm{min})$ & \multicolumn{1}{c}{ Surface } & $q_{\mathrm{CHF}}^{\prime \prime}\left(\mathrm{W} / \mathrm{cm}^{2}\right)$ & $q_{\mathrm{CHF}}^{\prime \prime} / q_{\mathrm{CHF}, \mathrm{S}}^{\prime \prime}$ \\
\hline \multirow{2}{*}{450} & Smooth & 25.6 & 1.00 \\
& Pin fin & 54.6 & 2.13 \\
& Coated flat & 37.5 & 1.46 \\
& Coated pin fin & 62.0 & 2.42 \\
900 & Smooth & 30.3 & 1.00 \\
& Pin fin & 61.6 & 2.03 \\
& Coated flat & 45.7 & 1.51 \\
& Coated pin fin & 68.0 & 2.24 \\
\multirow{4}{*}{1800} & Smooth & 46.9 & 1.00 \\
& Pin fin & 77.1 & 1.64 \\
& Coated flat & 62.2 & 1.33 \\
& Coated pin fin & 88.3 & 1.88 \\
\hline \hline
\end{tabular}

to nucleate and depart from the base of the finned surface, whereas a continuous vapor film is observed at heat fluxes above this operating point.

The design of the pin fins used in this study is evaluated based on the effective surface efficiency. As is shown in Fig. 8, the coated pin fins show distinctly lower effective surface efficiencies compared to the uncoated pin fins. This is due to the higher boiling heat transfer coefficients that result from the addition of the porous coating. Both surfaces show an initial decrease in surface efficiency with increasing heat flux (due to increasing boiling heat transfer coefficients) prior to a subsequent increase in efficiency at higher heat fluxes. This increase is consistent with the occurrence of dryout on the base surface. As the base surfaces of the fins become less effective at transferring heat due to vapor blanketing, the upper regions participate more in the overall heat transfer, leading to higher fin efficiencies. The minimum efficiencies of 0.8 for the uncoated pin fins, and 0.7 for the coated pin fins, highlight that further gains in heat transfer may be realized with increased area enhancement, through the use of longer or thinner, more densely packed fins.

3.2 Onset of Nucleate Boiling. The coated flat surface consistently requires a large surface superheat to initiate boiling

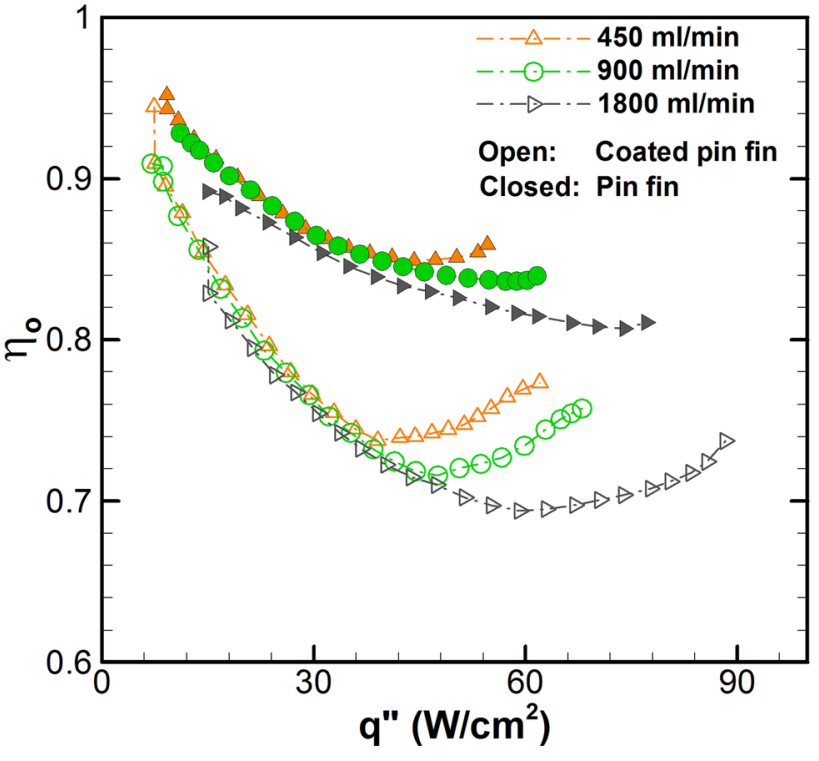

Fig. 8 Surface efficiency of the pin-fin and coated pin-fin surfaces for the single jet at all flow rates

(Fig. 6). The large overshoot is a result of the highly wetting HFE-7100 fluid thoroughly flooding all but the smallest nucleation sites on the surfaces after the rigorous surface degassing technique employed in this study. Similar results have been reported in the literature for porous surfaces with such surface preparation. Bergles and Chyu [16] found that the highly wetting R-113 effectively flooded the pores in their High Flux coating, resulting in ONB surface temperatures similar to that of a plain tube. Marto and Lepere [17] also found large temperature overshoots at ONB for Freon-113 and FC-72 from the High Flux coating, though slightly lower than that of their plain tube. The data for the coated flat surface in Fig. 6 display ONB surface superheats (approximately $20^{\circ} \mathrm{C}$ ) similar to the uncoated flat surface.

In every case tested, the pin-fin and coated pin-fin surfaces resulted in a small or negligible temperature overshoot at the ONB. The added surface area of the pin fins provides a greater number of potential nucleation sites and the fins also effectively

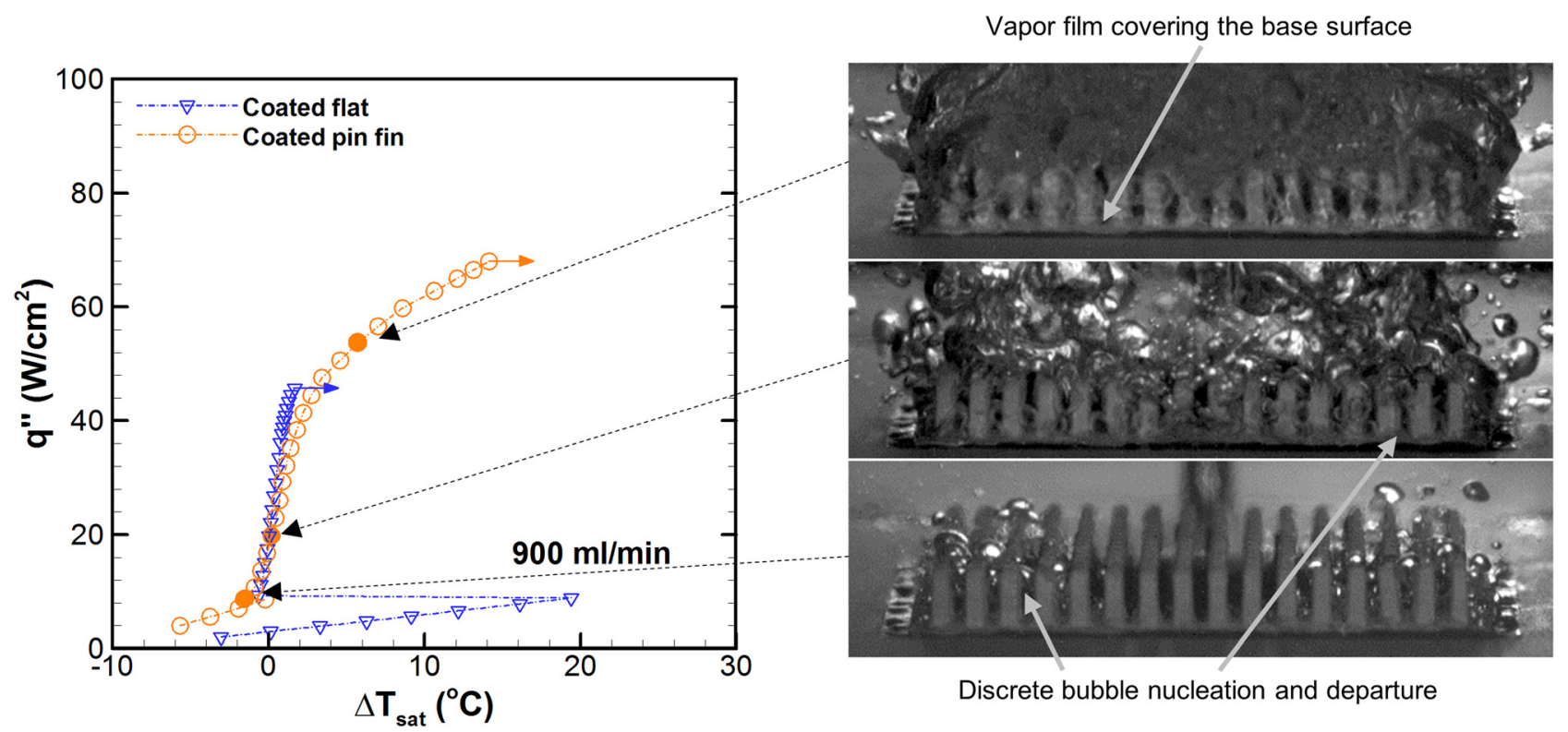

Fig. 7 High-speed images (right) of jet impingement on the coated pin-fin surface at $900 \mathrm{ml} / \mathrm{min}$ at the points highlighted (solid symbols) in the boiling curve (left); arrows indicate CHF. Supplementary video provided online [51]. 
superheat the fluid near the base and lower fin surfaces. The combined result is an increased likelihood that a large vapor embryo on the pin-fin surface will meet the boiling incipience criterion, leading to boiling beginning on the pin-fin surfaces at a lower wall superheat.

3.3 Effect of Flow Rate on Two-Phase Heat Transfer. Figure 9 compares the boiling curves at different flow rates. The boiling curves for the smooth and coated flat surface (shown in Fig. 9(a)) display an insensitivity to flow rate in the nucleate boiling regime. For the flat and coated flat surface, increasing the flow rate delayed ONB to a higher heat flux but also substantially extended CHF. Figure $9(b)$ shows the boiling curves for the pinfin and coated pin-fin surfaces. As with the flat surfaces, CHF for the pin-fin and coated pin-fin surfaces monotonically increases with increasing flow rate. At $1800 \mathrm{ml} / \mathrm{min}$, the boiling curves for both the pin-fin and coated pin-fin surfaces appear slightly shifted to lower wall superheats compared to the 900 and $450 \mathrm{ml} / \mathrm{min}$ cases. This leftward shift is indicative of the increased relative contribution of single-phase convective heat transfer at higher flow rates; the shift is correspondingly most prominent at low boiling heat fluxes (approximately $20 \mathrm{~W} / \mathrm{cm}^{2}$ ). This effect is more
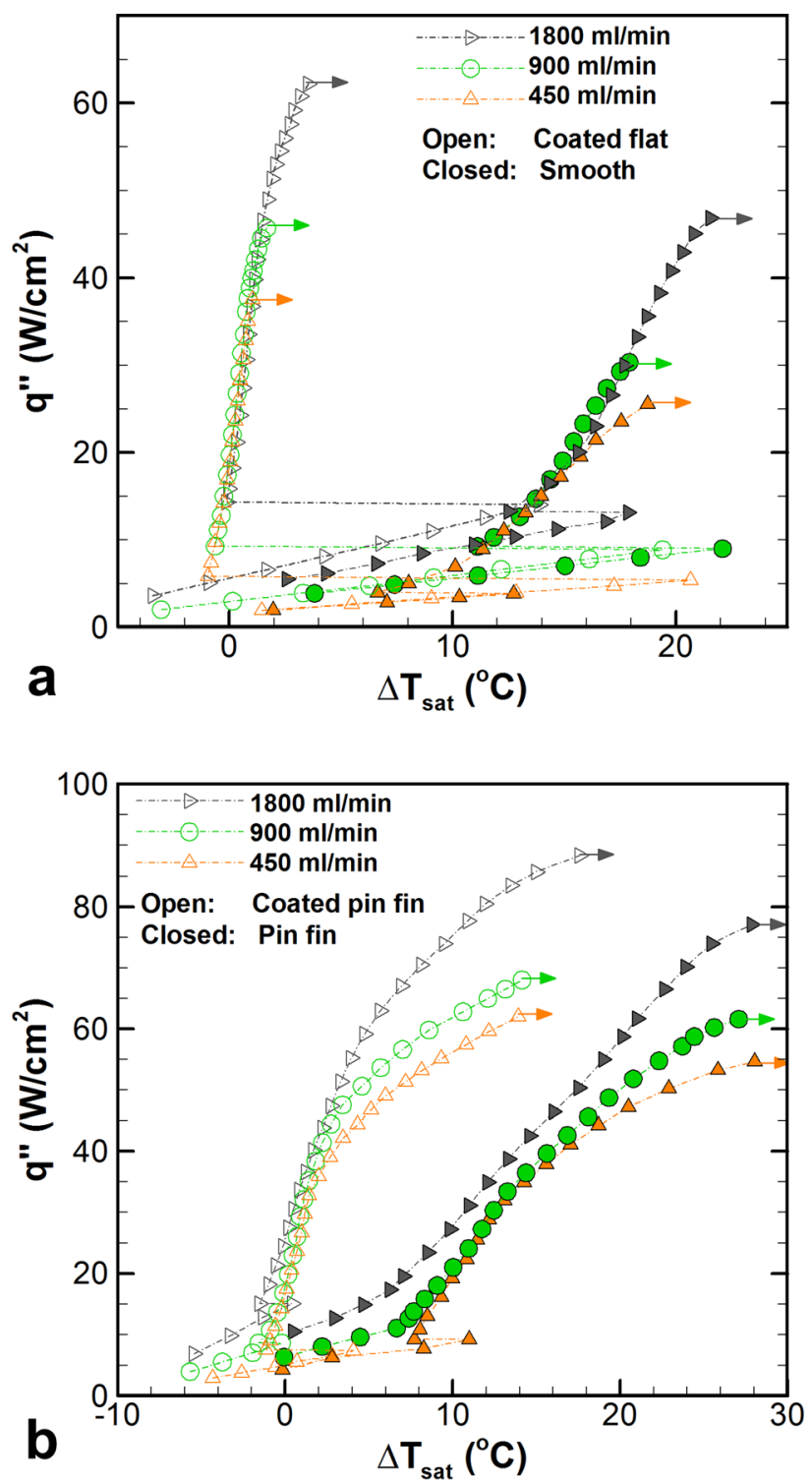

Fig. 9 Boiling curves at all flow rates for the (a) flat surfaces and (b) pin-fin surfaces; arrows indicate CHF prominent on the uncoated pin fins, as the extremely low boiling resistance provided by the coating overshadows the single-phase contribution to heat transfer. The smooth and coated flat surfaces, in contrast, show no leftward shift in fully developed nucleate boiling with increasing flow rate. For these surfaces, boiling dominates heat transfer and increased single-phase convection has a negligible effect on the overall heat dissipation.

3.4 Pressure Drop. The pressure drop across an enhanced two-phase impinging jet heat sink is of vital importance to its viability as a high-performance cooling technology. Thus, the pressure drop resulting from each experiment is measured. The test section instrumentation and the pressure drop measurement techniques utilized in this study are identical to those presented in Ref. [3], in which a validation of the measurement techniques was presented. Figure 10 presents the pressure drop at all flow rates measured for the four surfaces investigated in this work, as a function of applied heat flux. In all cases, the pressure drop remains constant and independent of heat flux throughout single- and twophase operation. Similar results were obtained in Ref. [3], where the pressure drop of a single jet and arrays of jets was found to be independent of vapor generation when impinging onto a smooth, stainless steel foil heat source. This behavior is extremely attractive from a cooling system design perspective, where the pressure drop can be assumed to be independent of vapor generation for pumping power calculations.

At all but the highest flow rate, the different surface enhancements did not result in measureable differences in the pressure drop of the impingement system. The overall confined jet pressure drop is dominated by the pressure drop across the sharp-edged orifice, with the two-phase conditions on the heater surface having a negligible influence. At $1800 \mathrm{ml} / \mathrm{min}$, a slight spread between the surfaces is observed, with the baseline smooth surface displaying the lowest pressure drop of $\sim 8 \mathrm{kPa}$ and the other three surfaces having a pressure drop of $\sim 8.5 \mathrm{kPa}$. The pin-fin and coated pin-fin surfaces would be expected to have a slightly higher pressure drop than the baseline surface as they offer some flow restriction to the jet after impingement; however, the coated flat surface also exhibits a higher pressure drop. Consistent with the earlier discussion of single-phase heat transfer enhancement at high jet velocities in Sec. 3.1, increased turbulence in the wall-jet boundary layer on the surface (induced by the effective roughness of the porous coating) could result in a higher pressure drop.

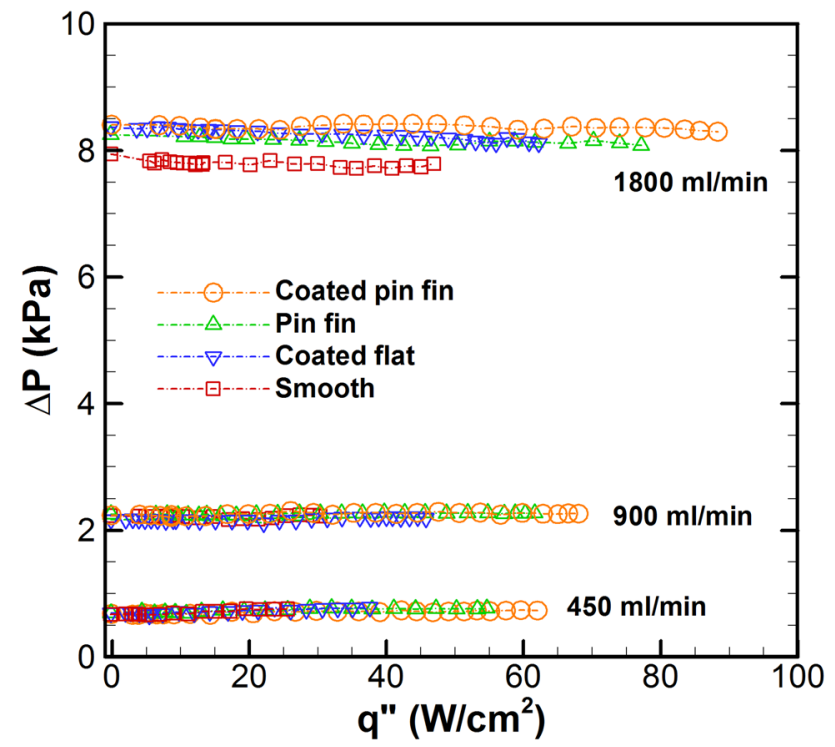

Fig. 10 Pressure drop for all flow rates and surfaces as a function of heat flux 


\section{Conclusions}

The heat transfer capabilities of a confined and submerged jet $(d=3.75 \mathrm{~mm})$ of HFE-7100 impinging on a variety of surface enhancements is investigated. The square pin fins and the microporous coating are evaluated as standalone surface enhancements. The enhancement characteristics provided by each surface (a flat surface coated with a microporous layer, a surface with macroscale pin-fin area enhancement, and a hybrid surface with pin fins coated with the microporous layer) are compared to a baseline smooth flat copper surface for heat transfer performance and pressure drop in single- and two-phase operation. Results are obtained at three different volumetric flow rates $(450,900$, and $1800 \mathrm{ml} / \mathrm{min})$.

The coated flat surface was found to generally provide no enhancement in single-phase heat transfer, but did not add any conduction thermal resistance compared to the baseline surface. Coated and uncoated extended fins provided significant enhancement in the single-phase heat transfer coefficient, a result of an approximately three times increase in surface area. A slight increase in single-phase performance for the coated surfaces at the highest jet velocities is attributed to increased turbulence in the wall-jet boundary layer.

In the two-phase regime, the addition of pin fins reduced the ONB temperature overshoot, decreased the nucleate boiling wall superheat by $\sim 6-8^{\circ} \mathrm{C}$, and enhanced CHF. The coated flat surface displayed very low wall superheats and enhancements in CHF; however, it also showed large incipience overshoot at ONB with incipience wall superheats similar to the baseline surface. The hybrid, coated pin-fin surface resulted in the most attractive characteristics. This surface displayed low incipience overshoot at ONB, low nucleate boiling wall superheats, and the highest CHF of all surfaces at every flow rate.

The boiling curves for both pin-fin surfaces demonstrated a reduced slope at high heat fluxes, which was attributed to dryout at the base of the fins. Minimum surface efficiencies for these surfaces ( 0.8 and 0.7 for the uncoated and coated pin fins, respectively), highlight that additional gains in heat transfer capabilities may be made with additional surface enhancement.

The pressure drop for all surfaces was found to be independent of heat flux and vapor generation, and the enhanced surfaces were found not to affect the pressure drop significantly.

\section{Acknowledgment}

The authors thank Toyota Motor Engineering and Manufacturing North America, Inc., specifically Dr. Eric Dede and Dr. Shailesh Joshi, for their support and technical discussions related to this work. The authors also thank Dr. Phillip Tuma of the $3 \mathrm{M}$ Company for applying the porous coating to the surfaces used in this work.

$$
\begin{aligned}
& \text { Nomenclature } \\
& A=\text { area } \\
& c_{\mathrm{p}}=\text { specific heat } \\
& d=\text { jet orifice diameter } \\
& h=\text { average heat transfer coefficient } \\
& H=\text { orifice-to-target spacing } \\
& k=\text { thermal conductivity } \\
& l=\text { length of orifice } \\
& L=\text { fin length } \\
& L_{\mathrm{c}}=\text { corrected fin length }(L+w / 4) \\
& N=\text { total number of fins } \\
& P=\text { electrical power input } \\
& q^{\prime \prime}=\text { average heat flux } \\
& q_{\text {loss }}=\text { heat lost to the ambient } \\
& \operatorname{Re}=\text { Reynolds number }(\rho V d / \mu) \\
& T=\text { surface temperature } \\
& T_{\mathrm{j}}=\text { jet inlet temperature }
\end{aligned}
$$

$$
\begin{aligned}
T_{\text {sat }} & =\text { saturation temperature of the fluid } \\
V & =\text { jet velocity } \\
w & =\text { fin width } \\
\triangle P & =\text { pressure drop }
\end{aligned}
$$

\section{Greek Symbols}

$\eta_{\mathrm{f}}=$ effective fin efficiency

$\eta_{\mathrm{o}}=$ effective surface efficiency

$\mu=$ dynamic fluid viscosity

$\rho=$ fluid density

\section{Subscripts}

$$
\begin{aligned}
\mathrm{b} & =\text { base } \\
\mathrm{CHF} & =\text { critical heat flux } \\
\text { eff } & =\text { effective } \\
\mathrm{f} & =\text { fin } \\
\mathrm{S} & =\text { smooth surface } \\
\mathrm{t} & =\text { total }
\end{aligned}
$$

\section{References}

[1] Garimella, S. V., 2000, "Heat Transfer and Flow Fields in Confined Jet Impingement," Annu. Rev. Heat Transfer, 11, pp. 413-494.

[2] Martin, H., 1977, "Heat and Mass Transfer Between Impinging Gas Jets and Solid Surfaces," Adv. Heat Transfer, 13, pp. 1-60.

[3] Rau, M. J., and Garimella, S. V., 2013, "Local Two-Phase Heat Transfer From Arrays of Confined and Submerged Impinging Jets," Int. J. Heat Mass Transfer, 67, pp. 487-498.

[4] Dukle, N. M., and Hollingsworth, D. K., 1996, "Liquid Crystal Images of the Transition From Jet Impingement Convection to Nucleate Boiling Part I: Monotonic Distribution of the Convection Coefficient," Exp. Therm. Fluid Sci., 12(3), pp. 274-287.

[5] Dukle, N. M., and Hollingsworth, D. K., 1996, "Liquid Crystal Images of the Transition From Jet Impingement Convection to Nucleate Boiling Part II: NonMonotonic Distribution of the Convection Coefficient," Exp. Therm. Fluid Sci., 12(3), pp. 288-297.

[6] Vader, D. T., Incropera, F. P., and Viskanta, R., 1992, "Convective Nucleate Boiling on a Heated Surface Cooled by an Impinging, Planar Jet of Water," ASME J. Heat Transfer, 114(1), pp. 152-160.

[7] Wolf, D. H., Incropera, F. P., and Viskanta, R., 1996, "Local Jet Impingement Boiling Heat Transfer," Int. J. Heat Mass Transfer, 39(7), pp. 1395-1406.

[8] Ma, C.-F., and Bergles, A. E., 1983, "Boiling Jet Impingement Cooling of Simulated Microelectronic Chips," Proceedings of the Symposium Heat Transfer in Electronic Equipment-1983, Boston, MA, Nov. 13-18, ASME, New York, Vol. 28, pp. 5-12.

[9] Zhou, D. W., and Ma, C. F., 2004, "Local Jet Impingement Boiling Heat Transfer With R113," Heat Mass Transfer, 40(6-7), pp. 539-549.

[10] Mitsutake, Y., and Monde, M., 2003, "Ultra High Critical Heat Flux During Forced Flow Boiling Heat Transfer With an Impinging Jet," ASME J. Heat Transfer, 125(6), pp. 1038-1045.

[11] 3M, 2009, 3M Thermal Management Fluids, 3M, St. Paul, MN, pp. 1-8.

[12] Webb, R. L., 1981, "The Evolution of Enhanced Surface Geometries for Nucleate Boiling," Heat Transfer Eng., 2(3-4), pp. 46-69.

[13] Webb, R. L., 1983, "Nucleate Boiling on Porous Coated Surface," Heat Transfer Eng., 4(3-4), pp. 71-82.

[14] Webb, R. L., 2004, "Odyssey of the Enhanced Boiling Surface," ASME J. Heat Transfer, 126(6), pp. 1051-1059.

[15] Honda, H., and Wei, J. J., 2004, "Enhanced Boiling Heat Transfer From Electronic Components by Use of Surface Microstructures," Exp. Therm. Fluid Sci., 28, pp. 159-169.

[16] Bergles, A. E., and Chyu, M. C., 1982, "Characteristics of Nucleate Pool Boiling From Porous Metallic Coatings,” ASME J. Heat Transfer, 104(2), pp. 279-285.

[17] Marto, P. J., and Lepere, V. J., 1982, "Pool Boiling Heat Transfer From Enhanced Surfaces to Dielectric Fluids," ASME J. Heat Transfer, 104(2), pp. 292-299.

[18] Thiagarajan, S. J., Wang, W., Yang, R., Narumanchi, S., and King, C., 2010, "Enhancement of Heat Transfer With Pool and Spray Impingement Boiling on Microporous and Nanowire Surface Coatings," ASME Paper No. IHTC1423284.

[19] 3M, 2009, 3M Microporous Metallic Boiling Enhancement Coating (BEC) L 20227, 3M, St. Paul, MN, pp. 1-2.

[20] El-Genk, M. S., and Ali, A. F., 2010, "Enhancement of Saturation Boiling of PF-5060 on Microporous Copper Dendrite Surfaces," ASME J. Heat Transfer, 132(7), p. 071501.

[21] You, S. M., Simon, T. W., and Bar-Cohen, A., 1992, “A Technique for Enhancing Boiling Heat Transfer With Application to Cooling of Electronic Equipment," IEEE Trans. Compon. Hybrids, 15(5), pp. 823-831.

[22] O'Connor, J. P., and You, S. M., 1995, “A Painting Technique to Enhance Pool Boiling Heat Transfer in Saturated FC-72," ASME J. Heat Transfer, 117(2), pp. 387-393. 
[23] Chang, J. Y., and You, S. M., 1997, "Boiling Heat Transfer Phenomena From Micro-Porous and Porous Surfaces in Saturated FC-72," Int. J. Heat Mass Transfer, 40(18), pp. 4437-4447.

[24] Chang, J. Y., and You, S. M., 1997, "Enhanced Boiling Heat Transfer From Micro-Porous Surfaces: Effects of a Coating Composition and Method,” Int. J. Heat Mass Transfer, 40(18), pp. 4449-4460.

[25] Chang, J. Y., and You, S. M., 1997, "Enhanced Boiling Heat Transfer From Micro-Porous Cylindrical Surfaces in Saturated FC-87 and R-123," ASME J. Heat Transfer, 119(2), pp. 319-325.

[26] Rainey, K. N., You, S. M., and Lee, S., 2003, "Effect of Pressure, Subcooling, and Dissolved Gas on Pool Boiling Heat Transfer From Microporous Surfaces in FC-72," ASME J. Heat Transfer, 125(1), pp. 75-83.

[27] Arik, M., Bar-Cohen, A., and You, S. M., 2007, "Enhancement of Pool Boiling Critical Heat Flux in Dielectric Liquids by Microporous Coatings," Int. J. Heat Mass Transfer, 50(5-6), pp. 997-1009.

[28] Ammerman, C. N., and You, S. M., 2001, "Enhancing Small-Channel Convective Boiling Performance Using a Microporous Surface Coating," ASME J. Heat Transfer, 123(5), pp. 976-983.

[29] Rainey, K. N., Li, G., and You, S. M., 2001, "Flow Boiling Heat Transfer From Plain and Microporous Coated Surfaces in Subcooled FC-72," ASME J. Heat Transfer, 123(5), pp. 918-925.

[30] Wadsworth, D. C., and Mudawar, I., 1992, "Enhancement of Single-Phase Heat Transfer and Critical Heat Flux From an Ultra-High-Flux Simulated Microelectronic Heat Source to a Rectangular Impinging Jet of Dielectric Liquid," ASME J. Heat Transfer, 114(3), pp. 764-768.

[31] Copeland, D., 1995, "Single-Phase and Boiling Cooling of Small Pin Fin Arrays by Multiple Slot Nozzle Suction and Impingement," IEEE Trans. Compon. Pack. A, 18(3), pp. 510-516.

[32] Anderson, T. M., and Mudawar, I., 1989, "Microelectronic Cooling by Enhanced Pool Boiling of a Dielectric Fluorocarbon Liquid," ASME J. Heat Transfer, 111(3), pp. 752-759.

[33] Guglielmini, G., Misale, M., and Schenone, C., 2002, "Boiling of Saturated FC-72 on Square Pin Fin Arrays," Int. J. Therm. Sci., 41(7), pp. 599-608.

[34] Parker, J. L., and El-Genk, M. S., 2009, "Saturation Boiling of HFE-7100 Dielectric Liquid on Copper Surfaces With Corner Pins at Different Inclinations," J. Enhanced Heat Transfer, 16(2), pp. 103-122.

[35] Klein, G. J., and Westwater, J. W., 1971, "Heat Transfer From Multiple Spines to Boiling Liquids," AIChE J., 17(5), pp. 1050-1056.

[36] Yu, C. K., and Lu, D. C., 2007, "Pool Boiling Heat Transfer on Horizontal Rectangular Fin Array in Saturated FC-72," Int. J. Heat Mass Transfer, 50, pp. $3624-3637$.
[37] Wei, J. J., and Honda, H., 2003, "Effects of Fin Geometry on Boiling Heat Transfer From Silicon Chips With Micro-Pin-Fins Immersed in FC-72," Int. J. Heat Mass Transfer, 46(21), pp. 4059-4070.

[38] McHale, J. P., Garimella, S. V., Fisher, T. S., and Powell, G. A., 2011, "Pool Boiling Performance Comparison of Smooth and Sintered Copper Surfaces With and Without Carbon Nanotubes," Nanoscale Microscale. Thermophys. Eng., 15(3), pp. 133-150.

[39] Rainey, K. N., and You, S. M., 2000, "Pool Boiling Heat Transfer From Plain and Microporous, Square Pin-Finned Surfaces in Saturated FC-72," ASME J. Heat Transfer, 122(3), pp. 509-516.

[40] Lay, J. H., and Dhir, V. K., 1995, "Nucleate Boiling Heat Flux Enhancement on Macro/Micro-Structured Surfaces Cooled by an Impinging Jet," J. Enhanced Heat Transfer, 2(3), pp. 177-188.

[41] Rau, M. J., Garimella, S. V., Dede, E. M., and Joshi, S. N., 2014, "Boiling Heat Transfer From an Array of Round Jets With Hybrid Surface Enhancements," ASME J. Heat Transfer, (in review).

[42] 3M, 2002, 3M Novec Engineered Fluid HFE-7100 for Heat Transfer, 3M, St. Paul, MN, pp. 1-8.

[43] Chen, T., and Garimella, S. V., 2006, "Effects of Dissolved Air on Subcooled Flow Boiling of a Dielectric Coolant in a Microchannel Heat Sink," ASME J. Electron. Packag., 128(4), pp. 398-404.

[44] Moreno, G., Narumanchi, S., and King, C., 2011, "Pool Boiling Heat Transfer Characteristics of HFO-1234yf With and Without Microporous-Enhanced Surfaces," ASME Paper No. IMECE2011-64002.

[45] Tuma, P. E., 2006, "Evaporator/Boiler Design for Thermosyphons Utilizing Segregated Hydrofluoroether Working Fluids," Proceedings of the 22nd Annual IEEE Semiconductor Thermal Measurement and Management Symposium, Dallas, TX, Mar. 14-16, pp. 69-77.

[46] ANSYS $®$ FLUENT, Academic Research, Release 14.0

[47] Jones, B. J., McHale, J. P., and Garimella, S. V., 2009, "The Influence of Surface Roughness on Nucleate Pool Boiling Heat Transfer," ASME J. Heat Transfer, 131(12), p. 121009

[48] Incropera, F. P., Dewitt, D. P., Bergman, T. L., and Lavine, A. S., 2007, Fundamentals of Heat and Mass Transfer, 6th ed., Wiley \& Sons, Hoboken, NJ.

[49] Bevington, P. R., and Robinson, D. K., 1992, Data Reduction and Error Analysis for the Physical Sciences, 2nd ed., McGraw-Hill, NY.

[50] Moreno, G., Narumanchi, S., Venson, T., and Bennion, K., 2013, "Microstructured Surfaces for Single-Phase Jet Impingement Heat Transfer Enhancement," ASME J. Therm. Sci. Eng. Appl., 5(3), p. 031004.

[51] "See supplementary material for high speed videos of the images shown in Fig. 7." 